Lourenço, A., \& Turner, S. (2019). The role of regulation in constituting markets: a co-evolutionary perspective on the UK television production sector. Journal of Institutional Economics, 15(4), 615630. https://doi.org/10.1017/S174413741900002X

\title{
The role of regulation in constituting markets: a co-evolutionary perspective on the UK television production sector
}

Ana Lourenço (corresponding author), Universidade Católica Portuguesa, Católica Porto Business School and CEGE, Porto, Portugal. E-mail: alourenco@porto.ucp.pt.

Simon Turner, Centre for Primary Care, Division of Population Health, Health Services Research and Primary Care, School of Health Sciences, Faculty of Biology, Medicine and Health, University of Manchester, Manchester, UK.

\begin{abstract}
This article builds on a legal institutionalist approach to assess market-based regulatory change in British television production over the last three decades. It explores how formal rules governing television production constitute market relations, and whether these rules are likely to be evaded by television producers and commissioners in a context where contracting depends heavily on social norms of cooperation, reciprocity and flexibility. Using qualitative data, this article suggests that changes in law and terms of trade intended to promote a market in television production have not had a straightforward or linear effect: compulsory independent production quotas and licensing models of terms of trade have redrawn organizational boundaries in unexpected ways, disturbed the public service remit and engendered new financial flows. Formal rules were nonetheless central to the trajectory of the television production industry, as they were a
\end{abstract}


constitutive element of changes in the power structure of the sector toward producers' interests.

Keywords: legal institutionalism; BBC; public service broadcasting; systems theory; television production. 


\section{Introduction}

Masterchef, Downton Abbey, Victoria are examples of UK originated television programmes or formats that have been broadcast worldwide, contributing to the $£ 2.7 \mathrm{bn}$ revenues generated in 2017 by the UK production market (PACT 2018). According to industry stakeholders such as PACT (Producers Alliance for Cinema and Television), OFCOM (the independent regulator and competition authority for communications) and UK government, part of the sector's good performance is associated with changes in regulation to enable market-based reform (PACT 2015; OFCOM 2015; Whittingdale 2015).

These changes include the creation of Channel 4 (1982) as an editorial channel funded by advertising; a 25\% quota for independent producers established in the 1990 Broadcasting Act; revised terms of trade that allow producers to retain and market residual property rights; and organizational responses to marketization by broadcasters, notably the $\mathrm{BBC}$, which created an additional $25 \%$ quota (the 'WOCC-Window of Creative Competition') within which in-house and independent producers compete for programme commissions. More recently, other reforms were introduced, such as the BBC's decision to remove its in-house guarantee of $50 \%$ and create $\mathrm{BBC}$ Studios, a wholly-owned subsidiary of the BBC Group that resulted from the merger of BBC Worldwide (content financing, sales and distribution arm) and BBC Studios (programme production arm). BBC Studios aimed to improve efficiency in production, maximize intellectual property from programming, and distribute British-made content as a 'cultural' export to global markets (BBC 2015a; DCMS 2016; BBC 2018).

This paper asks: how far are these changes delivering what was expected at the outset of reform? Have formal rules setting independent production quotas and licensing models of terms of trade been able to stimulate competition and diversity in television production? Is it likely that formal rules are evaded in a context where contracting depends heavily on norms emerging from personal and professional interactions within project networks? What can be said regarding the role of formal rules in constituting a market in television production? Answering these questions 
may illuminate discussion of the relevance of law for socio-economic activity in capitalist systems, or legal institutionalism (Deakin et al. 2017).

The assessment of the role of law in constituting markets in television production is explored from different theoretical perspectives on the influence of the institutional environment regarding contracts: (1) social systems theory, which assumes the simultaneous closure and openness of the legal and the economic systems, thus considering a non-linear relation between regulation and markets (Luhmann 1995 [1984]; Teubner 1992); (2) transaction cost economics, which views the legal system as an incentive mechanism and assumes an alignment between rules and economic action (Williamson 1975; 2000); (3) evolutionary game theoretic approaches that emphasize the role of institutions for economic agents' coordination (Sugden 1989; Boyer and Orléan 1992; Young 1996); and (4) the subset of epistemic game theory that stresses the role of formal rules as mediators of individual beliefs and social interactions (Aoki 2011). These perspectives are brought together given that their methodological assumptions, level of analysis and accounts of the nature, role and evolution of rules may be complementary and provide a more comprehensive lens to explore the trajectory of the UK independent production sector reform.

To answer the research questions, this study builds on qualitative material from various sources, collected at different points in time. 36 semi-structured, face-to-face interviews were conducted across the broadcasting industry in two waves: the first ( 21 interviews) between 2003 and 2004, and the second (15 interviews) in 2008. Interviews included producers and commissioners from all free-to-air television channels (14) and independent production companies (10), and also included professionals from Ofcom, a training centre, an investment bank's media unit, and BECTU, the UK media and entertainment trade union. Interviewees were selected according to access (which was facilitated by the use of a data-base of respondents from a previous study), snowballing and range (in regard to interviewees' role and to the status and dimension of their organization). An aide-memoire was drafted alongside the elements of regulatory change and interviews were conducted until there was a "strong sense of déja $v u$ " (Bryman 2004, p. 310) or saturation (Glaser and Strauss 1999). 
Interview data was triangulated with quantitative information on the composition of the television production sector and with documents analyzing the evolution of the broadcasting industry. These documents were of particular relevance to trace the trajectory of the broadcasting sector since 2008, given that a third wave of interviews was not achieved, and include annual account reports, public reports commissioned by the Government, the BBC and other entities, business reports of investment banks, press clippings and institutional presentations. Particular relevance was given to reports generated from the $\mathrm{BBC}$ charter renewal process, including the Government's Green Paper (DCMS 2015), the BBC's contribution to the public consultation (BBC 2015b), and Oliver \& Ohlbaum and Oxera's report assessing the market impact and distinctiveness of the BBC (2016).

Qualitative data was analyzed via coding and interpretation (Flick 2014). This process formed the basis for making substantive connections (Dey 1993): a picture of the interaction between elements of regulation and the constitution of markets in the independent television production industry started to build up.

This method is in line with a realist approach and its concern for the context of social interaction. As argued by Buchanan et al. "at the core of qualitative research is a particular ontological stance: it posits a social world that is multivariate, complex and open. The role of contingency in shaping social structures can be unveiled by studying a specific case in its local context" (2014, p. 14). In addition, it has been used in several studies focusing on understanding the complexity of the 'institutional fabrics' of economic activity (e.g. Olthaar et al. 2017; Mair et al. 2015), including television production (Doyle and Paterson 2008; Turner and Lourenço 2012; Paterson 2017b; D'Arma 2018). Despite the lack of interviews after 2008, this historical case study remains pertinent to understand a period of intense regulatory change in the television production industry, particularly the new terms of trade.

This paper starts with the perspective of social systems theory regarding the relation between formal rules and markets, contrasting it with transaction cost economics and game theories. The central claim is that markets can be constituted by, and respond to, formal rules, but 
not necessarily in a linear way, as if responding to rules. Then follows a description of the regulatory environment of television broadcasting and production that provides context for the case analyzed. Next, the trajectory of the independent television production sector in the UK in the last three decades is presented alongside the key elements governing it: independent quotas, terms of trade for production contracts; and norms governing project networks in television production. The paper concludes with a discussion of the role of independent quotas and terms of trade in (re)constituting a market in television production, assessing how far there is a linear or a co-evolutionary relation between law and markets, thus contributing to debate on the relevance of law for socio-economic activity.

\section{Contrasting perspectives on the role of formal rules in constituting markets}

The term 'formal rules' is used here to encompass rules that are designed to achieve a particular outcome and are sustained by public authority. That is the case of legal statutes setting compulsory independent quotas, and of terms of trade adopted by television broadcasters and monitored by Ofcom. The term contrasts with 'non-formal rules', which refers to conventions and social norms that emerge to coordinate human interaction and are enforced by social mechanisms, such as reputation. This is not to say that formal rules and non-formal rules are separate normative elements: formal rules are often the result of the institutionalization of non-formal rules, and the persistence and effectiveness of non-formal rules may be enhanced by formal rules (Armour and Deakin 2001). Both categories correspond to forms of regulation, but may be distinguished for an analytical purpose on the basis of their source and their enforcement mechanism.

Regarding the relation between formal rules and markets, there is not a uniform view. In social systems theory (Luhmann 1990; 1992; 1995 [1984]; Teubner 1992; 1993), law and the economy are understood as co-evolving social systems. Social systems - such as the legal or the economic ones - are viewed as systems of meanings that develop through a process of differentiation based on communication, that is, on a process of synthesis between information, 
utterance and understanding. Both systems are autopoietic, in the sense that they are selfreproducing ones: each has its own 'language', 'meanings' or 'code' - such as the 'legal/illegal' binary code of the legal system - that operationally closes the system, while at the same time allowing it to be cognitively open, that is, allowing it the possibility of 'observing' the world beyond its boundaries, by absorbing and internally processing the flow of information that comes from the exterior. Each system thus reads the environment, but in a manner that is conditioned by its own 'code' or mode of communication (Baxter 1998). While doing so, that social system builds forms of meaning: units of shared information that correspond to cognitive resources that reduce the complexity of the world (Carvalho and Deakin 2011).

Important consequences follow from assuming an autopoietic perspective of social systems for analysis of regulation. First, regulation is not restricted to statutory rules, but includes any rule, formal or non-formal, that invokes the code of the legal system, that is, the idea of legal validity (legal) or invalidity (illegal); regulation is 'decentred' (Black 2001). Second, the view of social systems as systems of meanings is aligned with a view of institutions as socially embedded systems of rules (Hodgson 2006), thus emphasizing the relevance of seeking to understand the role of law in society from a realist perspective. Third, there is a view of rules as cognitive resources that facilitate communication, stabilize expectations and reduce transaction costs (Deakin 2002), more than an emphasis on rules as constraining devices. Finally, there is a coevolutionary dynamic between rules and markets, as there is a mutual movement of capturing informational 'triggers' from the environment, interpreting and translating them, and then recodifying such information through internal systems of meaning, thus making sense of the world (Teubner 1992; Carvalho and Deakin 2011). This means that, for social systems theory, it may be that 'outcome B is aligned with regulation A', but this is not to be presupposed given that instances of interpretation, translation and re-codification are at play. Legal rules set to achieve a specific outcome may or may not have the expected result, depending on the way in which each system or indeed each community sharing a code of communication - observes and recodifies the new rules. 
A view of a co-evolutionary dynamic between rules and markets is in contrast with functional perspectives that emphasize a linear relation between rules and markets, such as transaction cost economics (Williamson 1975; 2000). Transaction-cost economics perceives rules as incentive mechanisms to which opportunistic and boundedly rational economic agents respond. Hence, rules consistently produce certain behavioral outcomes, which means that regulation may be designed so as to lead to previously identified aims. The adoption of broadcasting quotas for independent producers is an example of this type of 'design theory' (Pistor 2007): quotas are established by statutory law to open up the broadcasting schedule to independent producers to stimulate competition, range and diversity in television.

This linear view of the relation between rules and markets builds on a deductive methodology (Pratten 1997) and implies a 'command and control' perspective of rules: regulation is seen as the set of exogenous and given rules of the game according to which economic agents act. It is interesting to note that, while Williamson acknowledges the societal embeddedness of transactions and assumes the existence of interaction between regulation (including formal and non-formal norms) and markets (Williamson 2000), his concern for developing a prescriptive model of economic activity and retention of methodological individualism inhibits the consideration of regulation as an endogenous variable in his analytical model of governance (Hodgson 1989). On the whole, transaction cost economics posits that 'outcome B will follow regulation $\mathrm{A}^{\prime}$.

Examining the relation between rules and markets from the perspective of either social systems theory or transaction cost economics theory corresponds to taking extreme views, as a systemic theory is contrasted with a design one (Pistor 2007). Evolutionary and epistemic game theories (e.g. Sugden 1989; Young 1996; Aoki 2011) may be seen as a 'bridge' linking these two views.

Evolutionary game theory offers a third perspective on the relation between rules and markets which is neither a systemic nor a design one: regulation is endogeneized, as rules are understood to emerge through evolutionary processes of trial and error and imitation. Rules emerge from the gradual accretion of precedent strategies used in coordination games, being 
perceived as having worked in the past and are imitated, becoming self-enforcing patterns of behavior (Young 1996). This perspective does not correspond to a 'design theory'. It does not correspond to a systemic theory either, for the communicative and interpretive dimensions of human action are not at its centre: it grounds its explanation of how institutions emerge in a process based on observation and imitation of individual behaviour, not on a process centred on interpreting the environment and building 'meanings' of it.

Despite the endogeneization of rules and its concern for their evolution, there is a feature that evolutionary game theory shares with transaction cost economics: by viewing rules as emerging spontaneously from human interaction and being maintained through processes of observation and imitation, it assumes rules and economic action are aligned. In both theories, individuals act according to rules; the difference lies in the justification, which is the incentive nature of rules, for transaction cost economics, and the idea that individuals produce their own rules, for evolutionary game theory.

Gintis $(2009,2011)$ uses a game theoretical language to understand the process by which common knowledge is built, so that it can become a cue that facilitates individual coordination and cooperation. Gintis (2011) explains the evolutionary success of humans on the basis of a gene-culture coevolution: the human genome is able to encode stable aspects of the environment and pass these aspects on, but those aspects that are less stable require other non-genetic means of encoding and transmission, namely the encoding of culture into the human brain, transmitted via symbolic representations in the form of cultural artifacts. The behavioral routines on the basis of these representations feed back into the environment which, with time, will influence individual preferences and beliefs. This perspective implies a break from the individual centred view that infuses most game theory, since it recognizes the social embeddedness of the individual (Finch and McMaster 2017). Although this sociobiological perspective may uncover the relevance of common traits and cues genetically and socially encoded for human coordination and cooperation, its use requires caution when applied to the study of formal rules that are diverse and change rapidly across contemporary legal systems (Deakin 2011). 
Epistemic game theory, while also using the language of games to explain the role of institutions in coordinating individual behavior, represents a shift from evolutionary game theory, given its focus on the iteration between knowledge, beliefs, preferences and outcomes (Deakin 2011). Along with evolutionary game theory, the coordination of economic agents is seen as conditioned by a commonality, a stable cue that is shared by economic agents and forms the basis for ascribing probabilities to states of the world. However, epistemic game theory brings a forth perspective to the relation between rules and markets, since it emphasizes that those signals and cues include formal rules and other institutions that mediate individual beliefs and social interactions (Aoki 2011). These may be formalized on the basis of existing conventions and social norms (thus having an endogenous origin), but involve a process of decodification of conventions and recodification in formal rules that, once posited, are exogeneous to the economic actors. There is a dynamic of endogeneity and exogeneity that infuses Aoki's view of institutions as both cognitive media of agents' strategic interactions and their individual beliefs in societal games and as sources of codification and recodification that comes closer to the centrality of communication processes in social systems theory. Epistemic game theory thus represents a move from the view of alignment between rules and economic action, since it acknowledges a non-linear dynamic between signals or cues (societal artifacts such as rules and norms) and individual beliefs that are built within an environment that embodies those cues and in interaction with other individuals.

These four views of the relation between rules and markets have implications for regulatory reform, namely what to focus on and anticipated outcomes when altering extant formal rules to attain policy objectives: transaction cost economics focuses on the design of the rules so as to reach the desired outcome; by contrast, evolutionary game theory focuses on the emergence of social norms and implies a view of legal rules as a consequence of behavioral responses at a collective level; epistemic game theory focuses on the processes by which rules come to be commonly cognized patterns of behavior, as rules are viewed as societal artifacts that mediate behaviour and cognition to create and sustain social order; social systems theory focuses on the processes by which economic actors make sense of the rules, bringing attention to meaning as a foundation for human coordination. These different views, given their focus on design, outcomes, 
processes and meanings, may jointly assist in understanding how far should one expect legal rules and terms of trade posited to increase competition and diversity to deliver what was expected at the outset? And to what extent is it likely that legal rules and terms of trade are evaded in a context where contracting depends heavily on norms emerging from personal and professional interactions in project networks?

\section{The regulatory environment of television broadcasting and}

\section{production in the $\mathbf{U K}$}

The television production industry in the UK is an exemplary case of a sector regulated by a complex set of rules stemming from multiple sources: there are legal rules establishing independent production quotas, that is, percentages of the broadcasters' schedule that must be outsourced from independent producers; terms of trade intended to guide the programme supply process that result from initiatives of private ordering lobbied for by industry associations; and norms that emerge from project networks and other forms of professional organizations, based on reciprocity and trust, and on conventions of quality regarding programme content. The industry is also an exemplary case of hybridization (Turner et al. 2016), as the multi-layered effects of regulatory change have been informed by interactions at the organisational and professional level.

Legal rules at EU and national level regulate the independent television production sector. The main purpose of extant legal framework at the EU level is to create a European market for television programmes, based on the free circulation of transfrontier television programmes and on the establishment of broadcasting compulsory quotas. Independent production quotas are set in the Audiovisual Media Services Directive 2010/13/EU (article 17), and at the level of each Member State. In the UK, public service broadcasters are required to outsource a minimum of $25 \%$ of the total amount of time allocated to the broadcasting of qualifying programmes to the independent production industry (section 277, 2003 Communications Act). The rationale behind the creation of the independent quota was two-fold: to diversify the sources of programme supply, and to allow broadcasters to benchmark their costs against external suppliers (Peacock 1986; 
Deakin et al. 2009). In 2007 the WOCC was created at the BBC as an additional quota of $25 \%$ that both in-house and independent producers bid competitively for, with the aim of ensuring a level playing field between suppliers; but it has been perceived as detrimental to creativity (Nicoli 2012) and unsustainable (BBC Trust 2015). In the context of its Charter renewal in 2017, the BBC proposed to remove its in-house guarantee of $50 \%$, an offer endorsed by the Government (DCMS 2016).

In addition to legal rules, the television production industry is regulated by 'terms of trade'. These are general guidelines intended to assist independent producers through the commissioning process for the supply of programmes. A central aspect in terms of trade is the allocation of intellectual property rights (the 'rights deal'), which may follow two basic models: 'full-funding' and 'licensing'. Under the former model, the broadcaster pays in advance all or nearly all the budgeted costs of content development and production plus a production fee; in return, it acquires all rights in relation to the programme in perpetuity. Under the latter model, the independent producer funds the development costs and retains most rights to rebroadcast on other platforms (country and overseas), and to explore residual copyright and merchandising. The broadcaster is licensed for a limited number of showings over a fixed period of time, often with the option of an extension. Licensing models of terms of trade thus allow independent producers to build an asset that may be exploited in a number of ways - from 'remakes' to content adaptation for different creative output (e.g. games) and sales to a variety of channel aggregators - thus attracting external capital on the basis of future rents that will sustain growth. In the UK, following the review of the programme supply market by the former regulator (Independent Television Commission), and political lobbying by PACT, Ofcom recommended adoption of the licensing model (Ofcom 2004). Consequently, this model was adopted by broadcasters as a default rule.

The television production industry is shaped by norms linked to the cultural and experiential nature of television content: its value is derived from subjective experiences, meaning that it is difficult to measure the quality of programmes and to forecast their success. Producers are faced with highly unpredictable demand patterns, and production processes are difficult and costly to monitor and control (Lampel et al. 2000); in addition, the sector is strongly affected by 
technological change, where the element of risk is of paramount relevance (Doyle 2016). Tacit knowledge, instinctive judgements, talent and creativity are seen as crucial resources to produce and to commission successful programmes (Deakin and Pratten 2000; Ursell 2000; Preston 2003). To access these resources, broadcasters either vertically integrate production, thus controlling their technical and creative employees, or tend to develop long-term professional and personal relations with key independent producers whose reputation and experience in delivering quality programmes is known. These relational contracts correspond to structures of governance like project networks and latent organizations (Deakin and Pratten 2000; Starkey et al. 2000; Sydow and Staber 2002; Ebbers and Wijnberg 2016), where a broker brings together the professional skills needed for production for the time of its duration, thus building a network of professional and personal ties on which future dealings will rely. Norms of reciprocity, cooperation and flexibility bind production professionals into these hybrid organizations (Deakin and Pratten 2000, Deakin et al. 2009) but, at the same time, may work as barriers to diversity, as newcomers face difficulties in getting access to key decision-makers in the production process (Lee 2011).

The television production industry is regulated by a complex framework of rules and norms, providing an exemplary setting for assessing the role of rules in constituting or reconstituting market relations, exploring the extent to which there is a linear or a co-evolutionary relation between regulation and markets.

\section{Tracing the trajectory of the independent television production}

\section{industry in the UK}

The trajectory of the independent television production sector in the UK is presented alongside the elements of regulation that were designed to stimulate competition and diversity independent compulsory quotas and a licensing model of terms of trade - as well as those that emerged from economic agents' interaction - norms governing project networks in television production. 


\section{Perspectives on independent compulsory quotas}

The creation of Channel 4 as an editorial channel was perceived as a stimulus to the independent production sector, but not a sufficient one to sustain a competitive market. Though at first it was perceived as beneficial for the sector, evidence suggests that this was not a strong factor. During interviews, some industry actors reported a trend towards the development of inhouse production by editorial channels, and of de facto in-house production. The latter corresponds to forcing external independent producers to use the channel's resources, such as facilities (e.g. studios and post-production suites), technologies and personnel (e.g. camera crews, sound engineers). As one producer stated: "Channel 4 was moving into vertical integration, taking shareholders and suppliers. The argument was that vertical integrated organizations were needed because of the benefits of size for an international market" (second wave interviewing). Given this, compulsory independent production quotas were often seen as more apt at creating some kind of level playing field between independent producers and the broadcaster's internal production arms.

However, the sector was not of one view regarding the independent quota: whereas some actors - mostly within large independent producers - considered it a crucial element for stimulating the sector's growth, others did not ascribe it such a decisive role, as some felt the quota was adverse to the industry as a whole. On the one hand, some producers feared that without the quota, broadcasters would tend to favor in-house production. This was a perspective especially noted in the first round of interviews: "There are internal biases in favor of in-house production. Perhaps these things should be regulated until a real open market is implemented - in a sense that regulation is made to regulate. I used to feel that de-regulation was the answer, but we're not mature enough for it" (senior manager, production company). But on the other hand, industry actors added that the quota system per se was not a warrant of access to schedule. Producers claimed that unless a transparent bidding process was put in place, genuine access would not be available. As the senior manager of a production company stated: "It would be also good trying to make more transparent the in-house production system: in particular with factual TV, there is 
the problem of us presenting them an idea, and then they telling us afterwards that they were already working on something similar. Here we have no real protection" (first wave interviewing).

For other industry actors, the quota was seen as adverse to the industry. For some, it was perceived as creating a protective environment that undermines creativity and quality. As stated by an independent producer: "There's something about the temperament of an independent producer that makes him go hunting for something different. The problem is that we're still living in history: we're protected by the quota, which seems to me a necessary correction of the environment, but an undesirable one" (first wave interviewing). Additionally, there was distress that quotas might work as caps to be filled independently of quality, as one BBC manager stated: "I think we resist quotas as a means for determining production...we think it should be, we call it 'organic sustainable growth'. You should try and build something and make sure that people stay there. If you have quotas it has been proved over the centuries that if you have quotas, people find a way of filling them" (second wave interviewing). Moreover, during the second round of interviews, the WOCC was perceived as having the potential to lead to BBC's loss of critical mass necessary to invest in certain genres, given the increase in outsourcing, thus impairing onjob training.

As to the WOCC, the House of Commons' first report on the BBC Charter Review echoes different perspectives on its effects. On the one hand, it states that "this system appears to have been very successful in encouraging the growth and sustainability of the independent production sector in the UK. [...]" (House of Commons 2016, p. 23). But it also states that the WOCC is filled with commissions for long-running series of a small number of big producers, hence not working as a space for stimulating a competitive market in television production. Moreover, as the sector has become more consolidated and commercially driven, there is the danger for the $\mathrm{BBC}$ to lose key-staff to independent production companies, while finding it harder to meet the costs of high quality content that it has to deliver as a publicly funded broadcaster. This may compromise the BBC's ability to fulfill its remit of delivering quality content for all segments of the population. Against this background, the creation of BBC Studios as a commercial division 
that can produce content for other channels besides the $\mathrm{BBC}$, and has to keep separate accounts, may be interpreted as a means to retain key talent and foster creativity. However, recent news on the Government's will to mandate the disclosure of on-air top talent salaries over $£ 150,000$ has been claimed to undermine talent retention within the company (Martinson 2016), thus questioning the purpose of BBC Studios.

\section{Perspectives on the licensing model of terms of trade}

Regarding terms of trade, it is worth noting upfront a shift of focus from the first wave of interviews to the second, and then to more recent documental evidence: terms of trade increasingly surpassed independent quotas as the industry's dominant theme.

Interview materials suggest that in the beginning of 2000 , there was not a uniform perspective as to licensing models of terms of trade. Regarding the production side, larger independent production companies reacted positively to the new terms of trade, which they had been actively lobbying for under PACT, and understood them as a key factor sustaining their consolidation via external financing, international competition and ability to risk new content. These features were often highlighted during the interview process:

"In the past, TV producing was seen as a low margin and no rights industry. But now, if you have a secure 10\% return on investment, it is an attractive business. " (senior manager, large production company, first wave interviewing).

"The key thing from an external finance point of view is to get the rights; and the visibility of cash flow is more likely to come from that. The entertainment gets you merchandising and music creation, so there's a constant creation of rights" (media analyst, investment bank, first wave interviewing).

However, smaller production companies would often rather relinquish their intellectual property in exchange for contracts that provide them a guaranteed income on the basis of advance funding plus a production fee. As a senior manager of a production company argued: "Small producers want the production fee. Bigger producers want to explore the intellectual property 
involved" (first wave interviewing). Indeed, exploring increasing returns from content is a challenging trend for smaller firms who must develop new capabilities in international distribution, while managing to keep up with their production contracts, as it was acknowledged by the CEO of a trade association: "Indeed the benefits from the terms of trade have come through and they need managing and [knowing] where are the revenue streams and all the rest of it.[...] clearly there is another set of skills that most SME's wouldn't be familiar with, which is flotation, raising private financing, dealing with acquiring other companies to create groups" (second wave interviewing).

Regarding the broadcasting side, there was at first a negative reaction to the new terms of trade: broadcasters perceived them as endangering future strategies in the digital context, based on the exploitation of content on technological platforms, and commissioning editors felt that licensing contracts failed to recognize their creative input, especially when they initiated the commissioning process. Also, there was fear that growing outsourcing from independent producers might push broadcasters, and most notably the BBC, to adopt scheduling strategies increasingly driven by the independent sector and by viewing shares, thus disturbing not only the distinctive remit of public service broadcasting, but its very existence. Moreover, there were worries regarding the effects of new terms of trade on training and staff morale, given the increased competition within the WOCC and anticipated moves of top talent to commercial businesses.

Reaching this 'tipping point' whereby independent producers dominate broadcasting schedules (Hutton et al. 2005) has the potential to have significant impact on society. The retention of intellectual property by independent producers allows them to build assets that are able to be commercialized worldwide, gathering the interest of venture capital firms and other larger production companies willing to invest in acquiring content rights and talent for multiplatform consumption (Oliver \& Ohlbaum 2015). Actually, as they became interesting investment targets, production companies were involved in mergers and acquisition deals that altered the configuration of the industry, both in relation to its structure, which became more consolidated, and to the nationality of the main players, given that many of the large and super independent 
producers were acquired by international broadcasters, mostly from the USA (House of Commons 2016). It is not clear, though, whether this tipping point has been reached: for example, the deal involving the UK hit programme The Great British Bake Off, which switched broadcasting from the BBC into Channel 4, has been pictured as "signaling a shift in the balance of power between broadcasters and producers", but this perspective is not shared by representatives from the production side (Conlan 2016).

The international trade of content allowed broadcasters to manage the risk involved in programming: first, they can have access to production 'bibles' detailing viewing shares in specific demographic categories all across the world; second, additional sources of revenue may accrue from digital platforms consumption worldwide, backed by the brand power of formats such as The Voice or Masterchef, which do not customize their core brand (e.g. Masterchef Deutschland), thus potentiating worldwide visualizations - and corresponding advertising revenue - in video sharing websites. These risk managing strategies are of particular importance in a contracted economic context, given the increasing pressure on private and publicly owned companies to enlarge their duties while having to manage uncertainty over funding.

But these strategies may also hinder risk taking in innovative content, a remit that is at the heart of public service broadcasting. Whereas the emergence of 'super indies' allows them the financial slack to risk innovation, researchers emphasize that these efforts are targeted at a global audience, thus questioning the aim of increased programme diversity (e.g. Paterson 2017a; Nicoli 2012). Paterson (2017a) highlights that the limitations involved in preliminary studies that sustained regulatory change - namely the Phillis Report, which neglected the US experience and put excessive focus on content production, in detriment of distribution- impaired the full consideration of its potential effects. Moreover, production strategies focused on genres that are more easily traded in international markets (e.g. entertainment) may leave gaps in genres with lower residual value, but most relevant for an informed society, such as documentaries.

On the whole, against the backdrop of technological change allowing for new forms of viewing (e.g. time-shift, video-on-demand), terms of trade have stimulated the move of the independent television production industry from a 'cottage industry' into a fully commercial 
business (Mediatique 2005), where small independent production companies mostly dependent on one broadcaster for commissions and funding, coexist and compete with large companies that have been profiting from the ownership of intellectual property rights to attract venture capital funding, and develop new content that is being traded in the international broadcasting rights market. This competitive dynamic, however, is also at risk in face of the consolidation amongst 'super-indies' (Ofcom 2015; Abraham 2014; Freedman 2016) and of vertical integration amongst streaming providers (e.g. Netflix, Amazon). In face of the sector's trajectory, the DCMS advanced a proposal to review the terms of trade, which were maintained following Ofcom's view that they should not be changed (Ofcom 2015).

\section{Perspectives on norms governing project networks in television production}

Interview materials suggest that norms of reciprocity, cooperation and flexibility were critical in the UK for independent producers (even the larger ones) to get commissions and acquire the financial margin needed to risk producing pilot programmes.

On the one hand, the sector was characterized by a kind of 'corridor culture' which worked as a barrier to entry. The development of personal relationships with key people in the industry, namely commissioners, was viewed as critical to get commissions and acquire the stability needed to take risks in innovative content. A number of producers have a vantage point here: those who set up their production firms after having worked at a broadcaster, as well as those who are able to socially interact with commissioners (Paterson 2017b). This 'corridor culture' was perceived as an obstacle for producers based outside London, as well as for newcomers, who have to rapidly develop their network while having to assure the inception of their start-up companies. Despite the introduction of forms of electronic commissioning that allow for commissioners to publicize their priorities and for producers to present their proposals (e.g. BBC Pitch), findings suggest that personal ties are still important regarding access to project networks, and to less explicit information on what commissioners need. As stated by the commercial director at a large independent production company: 
"[...] the other key ingredient that I think all of us indies have is that we're looking for people out there who have got good relationships with the right people at Channel 4, Channel 5, $B B C$, and can therefore pick up the phone, walk in the door, even mention over lunch we've got a great idea. It also means that the broadcasters come to you first or come to these people first for things and that makes a huge difference" (second wave interviewing).

On the other hand, given the skills involved in producing television output, it is common for producers to work on the basis of a specific project, gathering around a broker the set of freelance specialized workers needed to complete it. The relationship developed with the programme's commissioner may become quite tight, allowing each professional to build conventions of programme quality that are not easily made explicit nor transactioned, and work as social capital in future dealings. As the head of department of a training centre argued: "There are technical standards, transmission standards, editorial standards, but not even in that can you see that a programme is of quality" (first wave interviewing).

The collaboration involved in these project networks favors the emergence of norms of reciprocity, collaboration and flexibility that run alongside formal elements of regulation. As stated by senior manager of a production company: "With Channel 4, the more we give them, the more we get. They reward us on the basis of the contribution we give them. Output deals usually appear as a gesture of good will after a very successful deal" (first wave interviewing).

Nonetheless, evidence also indicates a move towards the 'liberation' of the industry from these networking practices, as television programmes convert into a kind of commodity. For the entertainment genre, for instance, it is the availability of the right track record in terms of market research that sustains commissioning contracts, and not so much the control of key talent or the development of personal relationships. This is especially important for broadcasters that rely on entertainment formats to generate viewing shares, page visualizations and corresponding commercial revenue, but may not be as such for new players providing the television experience through streaming. For Netflix or Amazon, industry research has highlighted how the availability of a sizeable library, with high quality, exclusive and recent content and original series and movies 
are key factors of success, alongside, though, the availability of big data on consumption that allows for fine-tuned customer segmentation and targeting (PwC 2015).

In policy terms, there seems to have been a move from an emphasis on creative freedom, relational contracting and reputation to an emphasis on the television production sector contributing to economic growth as the sector consolidates (Paterson 2017b). If this move is accompanied by a reliance on metrics to evaluate the industry's contribution for economic growth, there is an additional tension on the BBC's remit, given that public service values are not as amenable to measure as audiences. As stated by a manager at the $\mathrm{BBC}$ : "One of the ironies of the fact that we now live in a measurement culture, where everything has to be audited and where key performance indicators are attached to everything, is that actually if you do that to television, or to media, you actually push the greatest of media towards increasingly worrying about things like ratings and being able to measure impact." (second wave interviewing).

\section{Discussing the trajectory of the independent television production industry in the UK}

The trajectory of the independent television production sector suggests that regulation aimed at increasing competition and diversity through independent quotas and new terms of trade affected the industry in complex ways.

On the one hand, norms of reciprocity, cooperation and flexibility within project networks seem to have played an important role in mediating the move towards a more market-orientated model of production. However, as the process of marketization deepens, there are signs that television programmes are converting into commodities. As consumer tastes shift rapidly, and content viewing platforms increase, relational contracts between commissioners and their preferred producers may be seen as binding broadcasters to producers which are not able to 'read' new trends and adapt their programming accordingly, thus putting the broadcasters' profitability in jeopardy. As the industry matures, big data analytics and production 'bibles' may be superseding conventions of quality as indicators of the content's future success. If that happens, 
production contracts will probably become relatively more discrete, coming closer to market relationships.

On the other hand, independent quotas and terms of trade seem to have had an impact on the emergence of new production companies and growth of the independent production industry as to revenues and exports, but also on the sector's consolidation, as larger independent production groups have been acquiring other production firms and building up catalogues of rights deals that become interesting assets for external finance. This consolidation trend has worked as a trigger for, paradoxically, both innovation and commodification: although television programming in free-to-air broadcasters seems to be increasingly homogeneous - as schedules are designed according to market research, and television formats and programmes are traded worldwide by 'super indies' - it is these 'super indies' that have the financial slack to risk and create new genres of programming and cross-genres that change the television landscape.

The trajectory of the independent television production sector suggests that legal rules setting compulsory independent quotas have operated alongside private forms of ordering, such as terms of trade negotiated by PACT to induce the liberalization of television production, and norms emerging from personal relationships between television professionals. These norms are built via the sharing of meanings involved in relational contracting, and the joint building-in of notions of quality facilitates the structural coupling between modes of governance and their economic environment. On the whole, the collected evidence suggests that the formal changes initiated by the quota system would not, on their own, have led to the growth of a successful independent sector in the UK; without the new terms of trade promoted by the Government following PACT's intense lobbying, and without norms sustaining relationships between producers and commissioners and their professional communities, it is unlikely that the production sector would have been as successful as it was regarding its transition from a 'cottage industry' into a fully commercial one.

Nonetheless, the experience of the licensing model of terms of trade suggests that changes in formal rules can sometimes destabilize social norms. The chain of events initiated by the new terms of trade, with the growing role of external finance and a shift in the balance of power from 
broadcasters to producers, has brought about a new commercialism as well as a sharper separation of interests, and possibly greater adversarialism in contractual relations, of which the negotiation of holdback periods is as example. Law has indeed worked as a central element of power, as it was both the object of PACT's lobbying effort to change terms of trade in favor of its constituents, and also the actor of the new power balance between broadcasters and producers. Insofar as these trends towards an increased adversarialism are linked to fears about the future capability of the industry for diversity, they put into question the effectiveness of the regulatory strategy implicit in the revisions to the terms of trade initiated in the early 2000 s.

\section{Conclusion}

Deakin et al. (2017) argue that social scientists have paid insufficient attention to the role of law in constituting the economic institutions of capitalism. This study addressed this gap by exploring the role of law and other elements of regulation in the marketization of the independent television production industry in the last three decades. A realist approach was adopted to explore how far formal rules delivered the expected competition and diversity in television production, and whether those rules were evaded in a context where contracting depends heavily on conventions and social norms of cooperation, reciprocity and flexibility emerging within project networks.

This study suggests that formal rules can indeed operate to constitute or stimulate markets, but not necessarily in a linear mode. The introduction of the compulsory independent quota did stimulate the emergence of new production companies and the opening up of schedules to independently produced content, and, in this sense, worked as an incentive mechanism of the kind posited by transaction cost economics. But since a number of these new companies were created by former in-house professionals that relied on relationships with former colleagues to get commissions, a full market in television production could not be claimed to exist. As to the new terms of trade, they did not result from the institutionalization of precedent practices, as evolutionary game theory would hypothesize, since full-funding models were the prevalent ones 
within the industry; they were 'championed' by larger production companies reliant on their ability to globally market intellectual property rights and may have contributed, at first, to the growth of the independent television sector (in number of companies and revenues) but also, more recently, to the consolidation of the sector and the commodification of television output. Hence, the study suggests that formal rules - in the form of compulsory quotas and terms of trade contributed to the transition of the independent production sector from a "cottage industry" into a competitive one, but have contributed paradoxically to its further consolidation, and to a decrease in investment in innovative and culturally distinctive content.

Formal rules were not evaded in a context where contracting depends heavily on conventions and social norms emerging within project networks; indeed, a more complex dynamic between non-formal and formal rules was found. Conventions of quality generated within communities of practice that sustained networks of broadcasting professionals, based on reciprocity, flexibility and cooperation, co-existed with the new terms of trade. But these norms that underpinned contracting in the early years following the liberalization of the industry are coming under pressure, and the stable equilibrium they provide may alter. When production companies were led by former in-house producers, relational norms of reciprocity and collaboration that crossed the boundaries of the broadcasting companies acted as commonly cognized patterns of behaviour, playing the mediating role posited by epistemic game theory. However, there is evidence that relationships between producers and broadcasters have become more arm's length, as producers' bargaining power has been enhanced by terms of trade and they have turned increasingly to venture capital for funding, which requires them to meet financial targets on a regular basis, and also as big data analytics and production 'bibles' supersede conventions of quality in the commissioning and production process, at least in what concerns the entertainment genre.

These trends are disturbing the public service remit at the $\mathrm{BBC}$, and its internal organization, of which the development of BBC Studios, a for-profit subsidiary, is a major sign. "Life-style" companies run by former in-house producers are becoming rarer and some of the personal networks which initially sustained the commissioning process are being lost as a result. 
The impact of changes in legal rules and terms of trade in constituting markets has been considerable, but not necessarily as predicted. If the rise of 'super indies' producing globally traded programmes means that they use their financial margin to risk financing new programmes and genres, and leave room for smaller companies to invest in less profitable but relevant genres such as documentaries, there would be a collateral result that, although not aligned with regulatory aims, might contribute to cultural public value. However, if the increased consolidation in television production means that producers reinterpret their role as contributors to economic growth, more than contributors to creative freedom, and target their producing efforts to global audience shares at the expense of innovation, not only is there non-linear result from regulatory change, but one that is detrimental to public value.

This study provides a contribution to legal institutionalism. It suggests that an understanding of the trajectory of independent television production in the UK in the last three decades cannot be explained solely from an 'incentive mechanism' perspective: it but requires a comprehensive view that takes into account the contributions of transaction cost economics, game theory and social systems theory to address regulatory design, outcomes and processes. However, these theories interpret 'rules' differently. In this paper, we have overcome potential conflict between the approaches by applying them to different stages of economic activity (design, outcomes, processes, and meanings). We recognize the need for further conceptual and empirical work that explores how the interplay between rules at each stage challenges assumptions about rules held in the theoretical approaches (e.g. how the role of rules in 'design' can be understood if this is shaped by 'meaning' in transaction cost economics, while making a conceptual space for the pre-existing aspects of experience or context that cannot be reduced to 'meaning' in social systems theory).

This comprehensive perspective has implications for policy-makers, who should not solely rely on the price-like role of formal rules posited by transaction cost economics, but also consider their reception by industry actors, that is, the way in which those rules are interpreted, recodified and acted upon by broadcasters and producers within the meanings developed in communities of practice and project networks. This calls for policy makers to utilize qualitative 
evaluations of the perceptions of broadcasters, producers and other constituents regarding the ways in which formal rules are influencing the constitution of markets, to the balance of power between industry actors and to the effects of shifts in power relations on content diversity. It also requires them to consider public policy developments in other countries and the balance of power of stakeholders involved in the definition of such policies, so as to anticipate possible dynamics of construction of meanings involved in the interaction between regulatory change and contracts. 


\section{References}

Abraham, David, 2014. MacTaggart Lecture at the Edinburgh TV Festival 2014. Available at https://www.theguardian.com/uk/media.

Aoki, Masahiko, 2011. Institutions as cognitive media between strategic interactions and individual beliefs. Journal of Economic Behavior \& Organization, 79, 1-2, pp. 30-34.

Armour, John; Deakin, Simon, 2001. Norms in private insolvency procedures: the "London Approach" to the resolution of financial distress. Journal of Corporate Law Studies, 1, 1, pp. 21-51.

Baxter, Hugh, 1998. Autopoiesis and the "relative autonomy" of law. Cardozo Law Review, 19,6, pp. 1987-2090.

BBC, 2015a. BBC Studios: Strengthening the BBC's role in the creative industries. London, BBC. Available at https://www.bbc.co.uk/aboutthebbc/.

BBC, 2015b. British, Bold, Creative: The BBC's programmes and services in the next charter. London, BBC. Available at https://www.bbc.co.uk/aboutthebbc/.

BBC, 2018. BBC Studios Annual Review. London, BBC. Available at https://www.bbcstudios.com/annual-review/.

BBC Trust, 2015. The supply arrangements for the production of the BBC's television content, radio content and online content and services. London: BBC. Available at http://downloads.bbc.co.uk/bbctrust. 
Black, Julia, 2001. Decentring regulation: understanding the role of regulation and self regulation in a "post-regulatory" world. Current Legal Problems, 54, 1, pp. 103-146.

Boyer, Robert; Orléan, André, 1992. How do conventions evolve? Journal of Evolutionary Economics, 2, pp. 165-177.

Bryman, Alan, 2004. Social research methods. Oxford: Oxford University Press.

Buchanan, John; Chai, Dominic Heesang; Deakin, Simon, 2014. Empirical analysis of legal institutions and institutional change: multiple-methods approaches and their application to corporate governance research. Journal of Institutional Economics, 10, 1, pp. 1-20.

Carvalho, Fábio; Deakin, Simon, 2011. System and evolution in corporate governance. In: Zumbansen, Peer; Calliess, Gralf-Peter (eds.) Law, Economics and Evolutionary Theory. Cheltenham, UK, Edward Elgar Publishing.

Conlan, Tara, 2016. Bake Off shows how TV's indies have learned the art of the deal. The Guardian, 17 September.

D’Arma, Alessandro, 2018. The hollowing out of public service media: a constructivist institutionalist analysis of the commercialisation of BBC's in-house production. Media, Culture \& Society, 40, 3, pp. 432-448.

DCMS-Department for Culture, Media and Sport, 2015. BBC Charter Review Public Consultation. DCMS, July. 
DCMS-Department for Culture, Media and Sport, 2016. A BBC for the future: a broadcaster of distinction. DCMS, May.

Deakin, Simon, 2002. Evolution for our time: A theory of legal memetics. Current Legal Problems, 55, 1, pp. 1-42.

Deakin, Simon; Lourenço, Ana; Pratten, Stephen, 2009. No "third way" for economic organization? Networks and quasi-markets in broadcasting. Industrial and Corporate Change, 18,1 , pp. 51-75.

Deakin, Simon, 2011. Legal evolution: Integrating economic and systemic approaches. Review of Law \& Economics, 7, 3, pp. 659-683.

Deakin, Simon; Gindis, David; Hodgson, Geoffrey; Huang, Kainan; Pistor, Katharina, 2017. Legal institutionalism: Capitalism and the constitutive role of law. Journal of Comparative Economics, 45, pp. 188-200.

Deakin, Simon; Pratten, Stephen, 2000. Quasi-markets, transaction costs, and trust: the uncertain effects of market reforms in British television production. Television \& New Media, 1,3 , pp. 321-354.

Dey, Ian, 1993. Qualitative data analysis. London, Routledge.

Doyle, Gillian, 2016. Managing in the distinctive economic context of media. In: Lowe, Gregory F.; Brown, Charles (eds.) Managing Media Firms and Industries: What's So Special About Media Management? London, Springer.

Doyle, Gillian; Paterson, Richard, 2008. Public policy and independent television production in the U.K. Journal of Media Business Studies, 5, 3, pp. 17-33. 
Ebbers, Joris; Wijnberg, Nachoem, 2016. Latent organizations in the film industry: contracts, rewards and resources. Human Relations, 62, 7, pp. 987-1009.

Finch, John H.; McMaster, Robert, 2017. History matters: on the mystifying appeal of Bowles and Gintis. Cambridge Journal of Economics, 42, 2, pp. 285-308.

Flick, Uwe, 2014. Mapping the field. In: Flick, Uwe (ed.) The SAGE Handbook of Qualitative Data Analysis. London, SAGE.

Freedman, Des, 2016. A future for public service television: content and platforms in a digital world. London, Goldsmiths, University of London.

Gintis, Herbert, 2009. The bounds of reason: Game theory and the unification of the behavioral sciences. Princeton, Princeton University Press.

Gintis, Herbert, 2011. Gene-culture coevolution and the nature of human sociality. Philosophical Transactions of The Royal Society B, 366, pp. 878-888.

Glaser, Barney; Strauss, Anselm, 1999. The discovery of grounded theory: strategies for qualitative research. New York, Aldine de Gruyter.

Hodgson, Geoffrey, 1989. Institutional economic theory: the old versus the new. Review of Political Economy, 1, 3, pp. 249-268.

Hodgson, Geoffrey, 2006. What are institutions? Journal of Economic Issues, XL, 1, pp. 1-25. 
House of Commons, 2016. BBC Charter Review: First Report of Session 2015-16. London, House of Commons, Culture, Media and Sport Committee.

Hutton, Will; O'Keeffe, Áine; Turner, Natalie, 2005. The tipping point: How much is broadcast creativity at risk? London: The Work Foundation in partnership with the BBC. Available at: http://www.theworkfoundation.com.

Lampel, Joseph; Lant, Theresa; Shamsie, Jamal, 2000. Balancing act: learning from organizing practices in cultural industries. Organization Science, 11, 3, pp. 263-269.

Lee, David, 2011. Networks, cultural capital and creative labour in the British television production industry. Media, Culture \& Society, 33, 4, pp. 549-565.

Luhmann, Niklas, 1990. Essays on self-reference. New York, Columbia University Press.

Luhmann, Niklas, 1992. Operational closure and structural coupling: the differentiation of the legal system. Cardozo Law Review, 13, 5, pp. 1419-1441.

Luhmann, Niklas, 1995 [1984]. Social Systems. Stanford, Stanford University Press.

Mair, Johanna; Mayer, Judith; Lutz, Eva, 2015. Navigating institutional plurality: organizational governance in hybrid organizations. Organization Studies, 36, 6, pp. 713-739.

Martinson, Jane, 2016. BBC presenters’ salaries over $£ 150,000$ to be made public. The Guardian, 14 September.

Mediatique, 2005. From the cottage to the City: the evolution of the UK independent production sector. London. 
Nicoli, Nicholas, 2012. BBC in-House production and the role of the window of creative competition. Journal of Media Business Studies, 9, 4, pp. 1-19.

Ofcom, 2004. Guidelines for broadcasters in drafting codes of practice for commissioning programmes from independent suppliers. London, Ofcom.

Ofcom, 2015. BBC Content Production Options - Ofcom's advice to the Secretary of State for Culture, Media and Sport. London: Ofcom. Available at https://www.ofcom.org.uk/.

Oliver \& Ohlbaum, 2015. Trends in TV Production. Presentation for Ofcom. Available at https://www.ofcom.org.uk.

Oliver \& Ohlbaum/Oxera, 2016. BBC television, radio and online services: An assessment of market impact and distinctiveness. Available at https://www.gov.uk/government/publications.

Olthaar, Matthias; Dolfsma, Wilfred; Lutz, Clemens; Noseleit, Florian, 2017. Markets and institutional swamps: tensions confronting entrepreneurs in developing countries. Journal of Institutional Economics, 13, 2, pp. 243-269.

PACT, 2015. Submission to Ofcom's third review of public service broadcasting: Public Service Content in a Connected Society. London, PACT. Available at https://www.ofcom.org.uk/.

PACT, 2018. UK Television Production Survey: Financial Census 2018. London, PACT. Available at http://www.pact.co.uk/. 
Paterson, Richard, 2017a. The competition discourse in British broadcasting policy. CREATe Working paper 2017/02. Glasgow, University of Glasgow.

Paterson, Richard, 2017b. Early independent production entrepreneurs in UK television: agents of a neo-liberal intervention. International Journal of Entrepreneurial Venture, 9, 3, pp. 280298.

Peacock, Alan, 1986. Report of the committee on financing the BBC. London, HMSO.

Pistor, Katharina, 2007. Legal systems in flux: analytical and methodological challenges. Conference on evolutionary and reflexive approaches to corporate governance. Cambridge, Center for Business Research.

Pratten, Stephen, 1997. The nature of transaction cost economics. Journal of Economic Issues, 31, 3, pp. 781-803.

Preston, Alison, 2003. Inside the commissioners. Glasgow, The Research Centre for Television and Interactivity.

PwC-PricewaterhouseCoopers, 2015. Outlook special: Over-the-top Television. Available at http://www.pwc.nl.

Starkey, Ken; Barnatt, Christopher; Tempest, Sue, 2000. Beyond networks and hierarchies: latent organizations in the U.K. television industry. Organization Science, 11, 3, pp. 299-305.

Sugden, Robert, 1989. Spontaneous order. Journal of Economic Perspectives, 3, 4, pp. 85-97. 
Sydow, Jörg; Staber, Udo, 2002. The institutional embeddedness of project networks: the case of content production in German television. Regional Studies, 36, 2, pp. 215-227.

Teubner, Gunther, 1992. The two faces of Janus: rethinking legal pluralism. Cardozo Law Review, 13, 5, pp. 1413-1462.

Teubner, Gunther, 1993. Law as an autopoietic system. Oxford, Blackwell.

Turner, Simon; Lourenço, Ana, 2012. Competition and public service broadcasting: stimulating creativity or servicing capital? Socio-Economic Review, 10, 3, pp. 497-523.

Turner, Simon; Lourenço, Ana; Allen, Pauline, 2016. Hybrids and professional communities: comparing UK reforms in healthcare, broadcasting, and postal services. Public Administration, 94, 3, pp. 700-716.

Ursell, Gillian, 2000. Television production: issues of exploitation, commodification and subjectivity in UK television labour markets. Media, Culture \& Society, 22, 6, pp. 805-825.

Whittingdale, John, 2015. Keynote speech at the Royal Television Society Cambridge convention. Available at https://www.youtube.com/.

Williamson, Oliver, 1975. Markets and hierarchies: analysis and antitrust implications. New York, The Free Press.

Williamson, Oliver, 2000. The new institutional economics: taking stock, looking ahead. Journal of Economic Literature, 38, 3, pp. 595-613. 
Young, H. Peyton, 1996. The economics of convention. Journal of Economic Perspectives, 10, 2, pp. 105-122. 